\title{
Reply to "Comment on 'Photoionization of helium atoms irradiated with intense vacuum ultraviolet free-electron laser light. Part I. Experimental study of multiphoton and single-photon processes",
}

\author{
T. Laarmann, ${ }^{1, *}$ A. R. B. de Castro, ${ }^{2}$ P. Gürtler, ${ }^{1}$ W. Laasch, ${ }^{1}$ J. Schulz, ${ }^{1, \dagger}$ H. Wabnitz, ${ }^{1}$ and T. Möller ${ }^{1,}$ \\ ${ }^{1}$ Hamburger Synchrotronstrahlungslabor HASYLAB at Deutsches Elektronen Synchrotron DESY, Notkestrasse 85, \\ 22607 Hamburg, Germany \\ ${ }^{2}$ Laboratorio Nacional de Luz. Sincrotron LNLS, 13084-971 Campinas SP, Brazil \\ and Instituto de Fisica Gleb Wataghin, Universidade Estadual de Campinas IFGW-UNICAMP, 13083-970 Campinas SP, Brazil
}

(Received 26 May 2006; published 6 September 2006)

\begin{abstract}
We do not agree with the conclusion of the Comment by Charalambidis et al. questioning our observation of two-photon ionization of helium by intense radiation with $13 \mathrm{eV}$ photons from a vuv free-electron laser. Two-photon ionization is clearly established by the detection of low-energy photoelectrons at $\sim 1.7 \mathrm{eV}$, which agrees very well with the expected energy for a two-photon ionization process.
\end{abstract}

DOI: $10.1103 /$ PhysRevA.74.037402

PACS number(s): 42.50.Hz, 33.60.Cv, 32.80.Rm

In our recent work [1], we presented a detailed study of photoionization of $\mathrm{He}$ atoms by intense vuv radiation from a free-electron laser (FEL). This new type of light source produces vuv light with an energy per pulse up to $100 \mu \mathrm{J}$ in the wavelength range $100-30 \mathrm{~nm}[2,3]$. Since the energy of this 25-50 fs long pulse is typically more than two orders of magnitude higher than that of high-harmonic generation (HHG) sources, they can very efficiently induce multiphoton processes. Multiphoton absorption and ionization are clearly established by recent work on rare gas clusters [4-6] and rare gas atoms (Xe, Ar) [7]. In atomic Xe beams, ions up to charge state $6+$ are observed which requires the absorption of more than 15 photons of $13 \mathrm{eV}$ energy. The validity of the results is underlined by a recent calculation by Santra et al. [8]. In our work on $\mathrm{He}$ criticized in the Comment by Charalambidis et al., we present a study with the same FEL source utilizing electron and mass spectroscopy. In contrast to mass spectroscopy, photoelectron spectroscopy allows a precise determination of the order of a multiphoton process, if - as in our case-the photon energy and the energy of photoelectrons are well defined. The motivation of this study was to disentangle various ionization processes which can take place, when intense FEL radiation interacts with matter. For an atomic He beam photoelectrons with a kinetic energy of $\sim 1.7 \mathrm{eV}$ are observed in Ref. [1]. This is in good agreement with the predicted value of $1.6 \mathrm{eV}$, if the absorption of two photons of $13.1 \mathrm{eV}$ by $\mathrm{He}$ atoms with a ionization energy of $24.6 \mathrm{eV}$ is assumed. We have studied the laser intensity dependence of this process in the range $3 \times 10^{10}-6$ $\times 10^{12} \mathrm{~W} / \mathrm{cm}^{2}$ which is significantly higher than in pioneering previous studies making use of HHG sources [9-11]. Data are recorded for different rare gas pressure and the possible contributions of residual gas are carefully taken into

\footnotetext{
*Present address: Max-Born-Institute, Max-Born Str. 2a, D-12489 Berlin, Germany.

${ }^{\dagger}$ Present address: MAX-lab, Box 118, 22100 Lund, Sweden.

*Present address: Institut for Atomic Physics PN 3.1, TU-Berlin, Hardenbergstr. 36, D-10623 Berlin, Germany.
}

account. ${ }^{1}$ A nonlinear dependence of the yield of photoelectrons is found with a slope varying between 1.2 and 1.65 (plotted on a log-log scale). The key argument in the Comment by Charalambidis et al. is that our assignment is wrong because their own pioneering experimental work on $\mathrm{He}$ at a substantial lower laser intensity, theoretical work and estimates give a slope close to 2, which is expected-as we all agree-for low intensity. The assignment in previous work [9-11] is just based on the measured slope. This was necessary because the HHG source used in those experiments contains several different harmonics and the ions are detected by mass spectroscopy. The determination of the slope is certainly useful to determine the order of multiphoton process, if no other information is available as in previous work [9-11]. In our case, however, we have much more direct information on the order of the multiphoton process since energy conservation allows a nonambiguous determination. Taking into account that a slope can only be determined with some error bar, especially if the intensity range is small, it is difficult to follow the arguments in the Comment. Moreover, we have good arguments that the experimentally observed deviation from a slope of 2 can be well explained.

Our results are supported by a recent calculation [12]. In this work two-photon ionization rates are calculated for $\mathrm{He}$ atoms under our experimental conditions by solving the time-dependent Schroedinger equation. As already stated in our paper [1] and in this theoretical study [12], interference effects explain the observed ionization rates and the deviation from the slope of 2. We like to stress that the theoretical model in Ref. [12] gives over many orders of magnitude up to $10^{11} \mathrm{~W} / \mathrm{cm}^{2}$ a slope of 2 . At higher laser intensity in the range $10^{11}-10^{14} \mathrm{~W} / \mathrm{cm}^{2}$ the slope shows an unusual variation. Values between 1 and up to 3 are derived. In their discussion of Figs. 6(a) and Fig. 9 of Ref. [1] the authors of the Comment missed an important aspect. Figure 6(a) shows

\footnotetext{
${ }^{1}$ We note that photoelectrons originating from water of the residual gas had been identified experimentally. The shown spectra in Fig. 5(a) of Ref. [1] had been corrected in terms of background contributions as described in the paper and thus are free from contaminations due to residual gas such as water or nitrogen.
} 
experimental and theoretical data points and the calculated nonmonotonic behavior of the two-photon absorption probability starts well below $10^{13} \mathrm{~W} / \mathrm{cm}^{2}$. Further, we like to point out that the deviation from the slope of 2 is not related to saturation effects as stated in the Comment. It seems that Charalambidis et al. are confusing the colloquial usage of the word saturation, meaning in the first case a large change of slope in the probability for two-photon absorption as a function of vuv laser intensity (which is the case in our work [1]), and a more technical usage meaning that "all atoms" in the interaction region were excited or ionized. Using the latter definition, we are in line with the authors of the Comment that saturation effects will occur at much higher vuv laser intensity, approximately at $10^{14} \mathrm{~W} / \mathrm{cm}^{2}$. It will be an interesting issue for future work to study the intensity dependence up to this regime.

In conclusion, we observed two-photon ionization in $\mathrm{He}$ atoms irradiated with intense vuv-FEL radiation and studied its intensity dependence up to $6 \times 10^{12} \mathrm{~W} / \mathrm{cm}^{2}$. We think that the ionization rate at high vuv intensities is an interesting phenomenon. As such, it might stimulate further experimental and theoretical work in this field.
[1] T. Laarmann, A. R. B. de Castro, J. Schulz, H. Wabnitz, and T. Möller, Phys. Rev. A 72, 023409 (2005).

[2] V. Ayvazyan N. Baboi, I. Bohnet, R. Brinkmann, M. Castellano, P. Castro, L. Catani, S. Choroba, A. Cianchi, M. Dohlus, H. T. Edwards, B. Faatz, A. A. Fateev, J. Feldhaus, K. Flöttmann, A. Gamp, T. Garvey, H. Genz, Ch. Gerth, V. Gretchko, B. Grigoryan, U. Hahn, C. Hessler, K. Honkavaara, M. Hüning, R. Ischebeck, M. Jablonka, T. Kamps, M. Körfer, M. Krassilnikov, J. Krzywinski, M. Liepe, A. Liero, T. Limberg, H. Loos, M. Luong, C. Magne, J. Menzel, P. Michelato, M. Minty, U. Müller, D. Nölle, A. Novokhatski, C. Pagani, F. Peters, J. Pflüger, P. Piot, L. Plucinski, K. Rehlich, I. Reyzl, A. Richter, J. Rossbach, E. L. Saldin, W. Sandner, H. Schlarb, G. Schmidt, P. Schmüser, J. R. Schneider, E. Schneidmiller, H. -J. Schreiber, S. Schreiber, D. Sertore, S. Setzer, S. Simrock, R. Sobierajski, B. Sonntag, B. Steeg, F. Stephan, K. P. Sytchev, K. Tiedtke, M. Tonutti, R. Treusch, D. Trines, D. Türke, V. Verzilov, R. Wanzenberg, T. Weiland, H. Weise, M. Wendt, I. Will, S. Wolff, K. Wittenburg, M. V. Yurkov, and K. Zapfe, Phys. Rev. Lett. 88, 104802 (2002).

[3] V. Ayvazyan, N. Baboi, J. Bähr, V. Balandin, B. Beutner, A. Brandt, I. Bohnet, A. Bolzmann, R. Brinkmann, O. I. Brovko, J. P. Carneiro, S. Casalbuoni, M. Castellano, P. Castro, L. Catani, E. Chiadroni, S. Choroba, A. Cianchi, H. DelsimHashemi, G. Di Pirro, M. Dolhus, S. Düsterer, H. T. Edwards, B. Faatz, A. A. Fateev, J. Feldhaus, K. Flöttmann, J. Frisch, L. Fröhlich, T. Garvey, U. Gensch, N. Golubeva, H. -J. Grabosh, B. Grigoryan, O. Grimm, U. Hahn, J. H. Han, M. V. Hartrott, K. Honkavaara, M. Hüning, R. Ischebeck, E. Jaeschke, M. Jablonka, R. Kammering, V. Katalev, B. Keitel, S. Khodyachykh, Y. Kim, V. Kocharyan, M. Körfer, M. Kollewe, D. Kostin, D. Krämer, M. Krassilnikov, G. Kube, L. Lilje, T. Limberg, D. Lipka, F. Löhl, M. Luong, C. Magne, J. Menzel, P. Michelato, V. Miltchev, M. Minty, W. D. Möller, L. Monaco, W. Müller, M. Nagl, O. Napoly, P. Nicolosi, D. Nölle, T. Nunez, A. Oppelt, C. Pagani, R. Paparella, B. Petersen, B. Petrosyan, J. Pflüger, P. Piot, E. Plönjes, L. Poletto, D. Proch,
D. Pugachov, K. Rehlich, D. Richter, S. Riemann, M. Ross, J. Rossbach, M. Sachwitz, L. Saldin, W. Sandner, H. Schlarb, B. Schmidt, M. Schmitz, P. Schmüser, J. R. Schneider, E. A. Schneidmiller, H. -J. Schreiber, S. Schreiber, A. V. Shabunov, D. Sertore, S. Setzer, S. Simrock, E. Sombrowski, L. Staykov, B. Steffen, F. Stephan, F. Stulle, K. P. Sytchev, H. Thom, K. Tiedtke, M. Tischer, R. Treusch, D. Trines, I. Tsakov, A. Vardanyan, R. Wanzenberg, T. Weiland, H. Weise, M. Wendt, I. Will, A. Winter, K. Wittenburg, M. V. Yurkov, I. Zagorodnov, P. Zambolin, and K. Zapfe, Eur. Phys. J. D 37, 297 (2006).

[4] H. Wabnitz, L. Bittner, A. R. B. de Castro, R. Döhrmann, P. Gürtler, T. Laarmann, W. Laasch, J. Schulz, A. Swiderski, K. von Haeften, T. Möller, B. Faatz, A. Fateev, J. Feldhaus, C. Gerth, U. Hahn, E. Saldin, E. Schneidmiller, K. Sytchev, K. Tiedtke, R. Treusch, and M. Yurkov, Nature (London) 420, 482 (2002).

[5] T. Laarmann, A. R. B. de Castro, P. Gürtler, W. Laasch, J. Schulz, H. Wabnitz, and T. Möller, Phys. Rev. Lett. 92, 143401 (2004).

[6] T. Laarmann, M. Rusek, H. Wabnitz, J. Schulz, A. R. B. de Castro, P. Gürtler, W. Laasch, and T. Möller, Phys. Rev. Lett. 95, 063402 (2005).

[7] H. Wabnitz, A. R. B. de Castro, P. Gürtler, T. Laarmann, W. Laasch, J. Schulz, and T. Möller, Phys. Rev. Lett. 94, 023001 (2005).

[8] R. Santra and C. H. Greene, Phys. Rev. A 70, 053401 (2004).

[9] P. Tzallas, D. Charalambidis, N. A. Papadogiannis, K. Witte, and G. D. Tsakiris, Nature (London) 426, 267 (2003).

[10] N. A. Papadogiannis, L. A. A. Nikolopoulos, D. Charalambidis, G. D. Tsakiris, P. Tzallas, and K. Witte, Appl. Phys. B 76, 721 (2003).

[11] N. A. Papadogiannis, L. A. A. Nikolopoulos, D. Charalambidis, G. D. Tsakiris, P. Tzallas, and K. Witte, Phys. Rev. Lett. 90, 133902 (2003).

[12] A. R. B. de Castro, T. Laarmann, J. Schulz, H. Wabnitz, and T. Möller, Phys. Rev. A 72, 023410 (2005). 